\title{
Methodology for Determining the Laboriousness of Assignments by Graphic Disciplines
}

\author{
Yskak Nabi: Department of Information Technologies, Consulting Methodical Center, Astana, Kazakhstan \\ -Umirbai Ibishev: Department of Mechanics, Kazakh National Agrarian University, Almaty, Kazakhstan.
}

\begin{abstract}
The objective of this study is to develop the methodology for determining the laboriousness of assignments by graphic disciplines. The results determined the volume of students' independent work performed on discipline "Descriptive Geometry and Engineering Graphics"; 2) determined the time expenses on 1 format A4 and indicated usage of this index to design the volume of students' independent work; 3) determined how much time reduced for expenditures to show the drawings using a computer; 4) show a comparison of $2 D$ and $3 D$ systems by the index of time expenses. Conclusion: The obtained data gives the ability to determine the student's independently work laboriousness.
\end{abstract}

Key words: Graphic disciplines, Kazakhstan, Laboriousness of assignments, Time expenses.

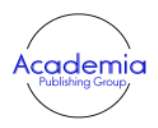

International Journal of Educational Studies Vol. 1, No. 2, pp. 141-148

2018

DOI: $10.53935 / 2641-533 x . v 1 i 2.82$

Corresponding Author: Umirbai Ibishev

Funding: This study received no specific

financial support.

Article History:

Received: 29 May 2018

Revised: 5 October 2018

Accepted: 26 November 2018

Published: 21 December 2018

(๑) 2018 by the authors; licensee Academic Publishing Group

\section{Introduction}

The problem of designing students' independent work on graphic disciplines is a special object of our perennial researches. Low level of student's self-learning activity formation leads to shortcomings in their professional activities in the future. Failure to do so is that future specialists are a consequence that the use of scientifically proven and practice-tested approaches in higher education institutions activity is insufficient. That's why the organization of students' independent work is one of the most important directs in the learning process. We aim to realize this direction on the example of designing the independent work of the student on disciplines "Descriptive Geometry and Engineering Graphics" and "Computer Graphics". To achieve this goal, we set ourselves the tasks: 1) to determine the volume of students' independent work showed on discipline "Descriptive Geometry and Engineering Graphics"; 2) to determine the time expenditure on 1 format A4 and indicate how to use this index to design the volume of students' independent work. It is wellknown that drawing on the computer reduces the amount of work and improves the drawings quality. But there is no real data about how much time is spent. Also, there is no information about the difference in time spent while draw using a computer in $2 \mathrm{D}$ or $3 \mathrm{D}$ systems. That is why we have to set the following tasks additionally to specified one: 3 ) to determine how much time is reduced the expenditures to show the drawings using a computer; 4 ) to compare the $2 \mathrm{D}$ and $3 \mathrm{D}$ systems by the index of time expenses.

\section{Methodologies}

\subsection{Methods of Students' Time Fund Research}

The methods of students' time fund research are: questioning: the tested person answer the question the result is determined the amount of time expenses on different activities;

i) A method of the past remembering: the amount of time expenses is determined on the memory of the 


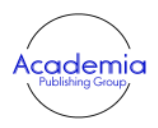

International Journal of Educational Studies Vol. 1, No. 2, pp. 141-148 2018

DOI: $10.53935 / 2641-533 x$ v vi2 82

- Corresponding Author: Umirbai Ibishev Funding: This study received no specific financial support. Article History:

Received: 29 May 2018

Revised: 5 October 2018

Accepted: 26 November 2018

Published: 21 December 2018

() 2018 by the authors; licensee Academic Publishing Group tested person;

ii) Motion-time study: the researcher determine the time expenses of the tested person by the visual examination;

iii) Self-registration of time expenses: the tested person enter the necessary data on the chronometry card. There are two types of chronometry cards: closed (reduced in conventional form) and open (not reduced in conventional form). Using the first chronometry card type the registration is carried out according to the structure established by the researcher. In this case you can easily find the amount of time expenses. The second chronometry card type gives a possibility to the tested person to easily register the time expenses.

These methods have advantages and disadvantages. When answering the questions in the questionnaire, the time expenses by the tested person on other types of activities are ignored. Data on the method of remembering the past is quickly collected, but their accuracy is doubtful. The motion-time study provides high accuracy, but requires a lot of effort and time and it is not always effective.

It is difficult to fill in a chronometry card with a conventional form, but the researcher will be able to process the data. When processing the second type of chronometry card the laboriousness will be higher because obtained data necessary enter in table with the conditional form.

The self-registration of time expenses method allows many people to participate in the test therefore is provided the study representativeness and the obtained data accuracy. In this regard, often used in statistical research. For example, this method was used to determine the student's time budget in Kazakh National Agrarian University (Nabi, Kampitova, \& Kucherbaev, 2009). The results of the study show that the student's time at the classroom is 4.52 hours per day and is approximately the same for all faculties; and the time expenses on a student's independent work depends on the student's future profession, so students of technical faculties (engineering, energy and information systems) work more in the library and at home therefore the time budget is more than students of biological specialty, namely $10.2 \ldots 9.2$ hours and 8.2 hours 6.8 hours accordingly.

Prof. Y. Nabi used the described method for extensive and profound research. The results of this study are shown in his monograph (Nabi, 1996). The general idea was derived from the dissertation (Verhela, 1988). The author of this dissertation has developed a method of determination the norm of the student's independent work and made the experimental research at the Kiev Institute of Food Industry. The basis of the methodology is dividing work on topics for certain periods. For example, the algorithm to show tasks on the drawing subject is:

1) Acquaintance with the task, its analysis;

2) Mastering the theoretical material in the textbook;

3) Organize the workplace, prepare tools;

4) Fill out the main inscription and draw the field frame;

5) Define the main view of the object or the detail and the images minimum number;

6) Assign a scale, arrange the images:

7) Draw given data of the task;

8) Draw required images;

9) Draw the dimensional lines and mark the numbers;

10) Mark the surface roughness designation;

11) Final decor of the drawing (hatching, writing and so on);

12) Draw the main lines of the drawing;

13) Check the drawings, make necessary corrections.

\subsection{The Expert Method}

The expert method is a complex of logical and mathematical procedures aimed to obtain information, analyze it and generalize it with the purpose of preparing and accepting a competent managerial decision. The essence of the method consists of conducting by expert's analysis of the problem with qualitative and quantitative evaluation of judgments and formal processing of the results by individual expert assessments. The expert assessments method allows you to analyze complex pedagogical processes, phenomena or situations, which are characterized mainly by qualitative, non-formalizable signs, which makes their analysis and evaluation difficult. This method has logically interrelated stages, which are the main stages of 


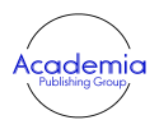

International Journal of Educational Studies Vol. 1, No. 2, pp. 141-148

2018

DOI: $10.53935 / 2641-533 x . v 1 i 2.82$

a Corresponding Author: Umirbai Ibishev

Funding: This study received no specific

financial support.

Received: 29 May 2018

Revised: 5 October 2018

Accepted: 26 November 2018

Published: 21 December 2018

(C) 2018 by the authors; licensee Academic Publishing Group pedagogical expertise. The initial stage (organization of expertise) includes: the definition of the purpose and objects of the expertise, the formulation of the problem, the selection of experts,

The main stage of the expertise is related to the collection of data, the conduct of research work and expert evaluation, an analysis of available material. The technology of expertise is to use the methods and evaluation criteria which depend on the character of the expertise, fill the application field (Kolesnikova, 2015).

For the pedagogical expertise often requires the development of questionnaires, interrogations, tests, control and diagnostic tasks. The final stage of the expertise is the questioning by experts (individual or group, personal, internal or external, oral or written), document processing (report, reference, review, etc.), and acceptance of expert opinion.

In our case, it is advisable to use individual expert assessments, because we wanted to know the opinions of experts from different universities so that they did not contact to each other. Therefore, we used questionnaires and appealed to experts with this request:

"Assess the justification of the methodology of determining the time expenses on the work of the student out of the classroom

a) The methodology is well-founded and applicable;

b) The methodology is valid, but it requires a lot of time and efforts to implement it;

c) The methodology is valid, but there are the doubt because it is based on experimental data collection;

d) The methodology is valid, but it must be strictly theoretically grounded;

e) The methodology is not applicable".

\section{Results and Discussion}

An importance of an idea of the proposed methodology is to show that work is divided into periods. However, according to Nabi (1996) the given task shows that algorithm is based on small operations adapted to each topic, so he suggested his own algorithm. This algorithm consists of six stages, suitable for any task. The order of these periods, as well as the amount of time expenses by the students, show tasks for self-study out of the classroom by Descriptive Geometry is shown in Table 1. That they will need for comparison.

In the 80-th years of the last century information on all topics was collected. For this work was used the questionnaires on form shown in Table 1 and were distributed by students of the Kazakh Agricultural Institute. The results of this data processing are shown in paper (Vdovin, 1984).

Table-1. Time expenses for performing and share of each task.

\begin{tabular}{|c|c|c|c|c|c|c|c|c|}
\hline $\begin{array}{l}\text { Performing } \\
\text { stages }\end{array}$ & $\begin{array}{l}\text { Time exp } \\
\text { of assignı } \\
\text { of task } \\
\# 1\end{array}$ & $\begin{array}{l}\text { enses for } \mathrm{F} \\
\text { nent \#1 } \\
\text { of task } \\
\# 2\end{array}$ & $\begin{array}{l}\text { performing } \\
\text { of task } \\
\# 3\end{array}$ & of task & $\begin{array}{l}\text { of assignr } \\
\text { of task } \\
\# 1\end{array}$ & $\begin{array}{c}\text { ment \#2 } \\
\text { of task } \\
\# 2\end{array}$ & $\begin{array}{l}\text { on full } \\
\text { work } \\
\text { stage }\end{array}$ & $\begin{array}{l}\text { Per cent to } \\
\text { summary } \\
\text { time }\end{array}$ \\
\hline $\begin{array}{l}\text { Getting } \\
\text { acquainted } \\
\text { with the task, } \\
\text { reading } \\
\text { literature on } \\
\text { the } \\
\text { topic }\end{array}$ & 31 & 27 & 29 & 30 & 126 & 51 & 294 & 15 \\
\hline $\begin{array}{l}\text { Drawing on the } \\
\text { drafting paper }\end{array}$ & 45 & 54 & 43 & 52 & 196 & 34 & 424 & 22 \\
\hline Consultation & 17 & 9 & 13 & 12 & 58 & 32 & 141 & 7 \\
\hline $\begin{array}{l}\text { Drawing on the } \\
\text { whatman paper }\end{array}$ & 44 & 39 & 42 & 51 & 291 & 98 & 565 & 29 \\
\hline $\begin{array}{l}\text { Revising after } \\
\text { checking }\end{array}$ & 22 & 15 & 23 & 19 & 244 & 58 & 381 & 19 \\
\hline $\begin{array}{l}\text { Decor of the } \\
\text { drawing }\end{array}$ & 22 & 23 & 22 & 24 & 40 & 20 & 151 & 8 \\
\hline SUM & 181 & 167 & 172 & 188 & 955 & 293 & 1956 & 100 \\
\hline
\end{tabular}




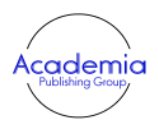

International Journal of Educational Studies Vol. 1, No. 2, pp. 141-148

2018

DOI: $10.53935 / 2641-533 x . v 1 i 2.82$

* Corresponding Author: Umirbai Ibishev

Funding: This study received no specific

financial support.

ticle History:

Received: 29 May 2018

Revised: 5 October 2018

Accepted: 26 November 2018

Published: 21 December 2018

(C) 2018 by the authors; licensee Academic Publishing Group
We did the same research in 2006-2009 at the Kazakh National Agrarian University. The questionnaire form for determining the time expenses on a student's independent work on graphic disciplines and the received information data are shown in Table 2. It is important to note that the questionnaire form has changed. If earlier a questionnaire was given for each task, then they were merged and distributed in one questionnaire. The reason is that earlier such tasks were carried out during three semesters, and now, in the credit technology conditions, showed in one semester.

Table 3 shows the sum of time expenses per hour on each topic, according to the task topic, the number of A4 formats and laboriousness which is found by means of division this sum on the A4 formats number. In the previous ("linear") system and in the current system, i.e. in the undergraduate, it is possible to notice that there are some laws and differences as well.

Table-2. Time value spended for work type (in minutes).

\begin{tabular}{|c|c|c|c|c|c|c|c|}
\hline $\begin{array}{l}\text { Assessment } \\
\text { topic }\end{array}$ & 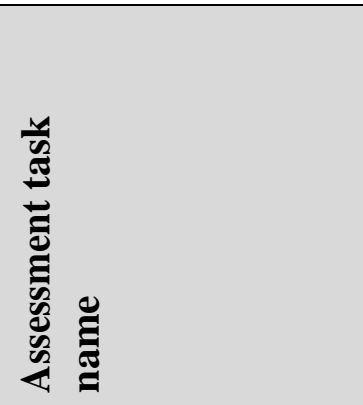 & 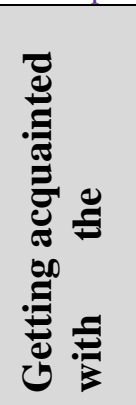 & 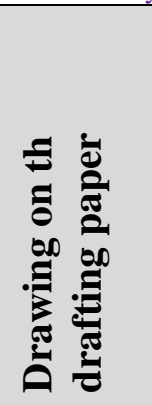 & 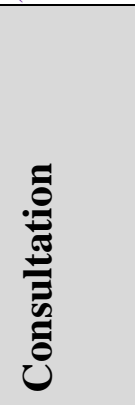 & 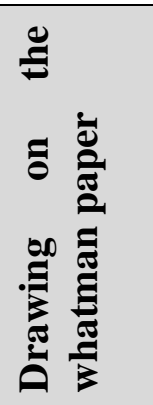 & 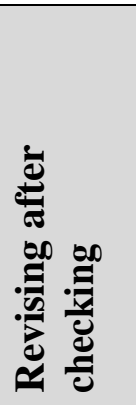 & 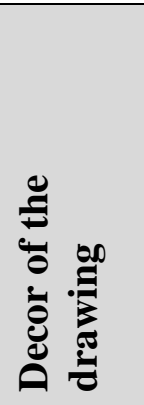 \\
\hline \multicolumn{8}{|c|}{ Section "Descriptive geometry" } \\
\hline & task \#1 & 14.12 & 29.48 & 5.70 & 37.86 & 5.07 & 14.35 \\
\hline \multirow{3}{*}{ Assignment \#1 } & task \#2 & 12.61 & 26.36 & 3.39 & 37.49 & 4.80 & 13.32 \\
\hline & task \#3 & 11.41 & 26.36 & 3.70 & 34.86 & 4.25 & 12.91 \\
\hline & task \#4 & 10.77 & 25.46 & 4.42 & 36.17 & 4.20 & 13.20 \\
\hline Total & & 48.90 & 107.67 & 17.20 & 146.38 & 18.32 & 53.78 \\
\hline \multirow[t]{2}{*}{ Assignment \#2 } & $\begin{array}{l}\text { Construction of the } \\
\text { intersection line }\end{array}$ & 742 & 3068 & 539 & 3978 & 359 & 1338 \\
\hline & $\begin{array}{l}\text { Construction of the } \\
\text { development }\end{array}$ & 7.71 & 26.10 & 5.23 & 33.68 & 4.61 & 10.59 \\
\hline \multicolumn{2}{|l|}{ Total } & 15.13 & 56.78 & 10.62 & 73.46 & 8.20 & 23.97 \\
\hline \multicolumn{2}{|c|}{ Total by section } & \multicolumn{5}{|c|}{ Section "Engineering graphics" } & 77.75 \\
\hline \multirow[t]{2}{*}{ Decor of drawing } & Lettering & 15.75 & 51.67 & 3.64 & 113.26 & 9.71 & 16.83 \\
\hline & Dimensioning & 10.01 & 32.49 & 3.33 & 80.84 & 13.75 & 15.16 \\
\hline Geometric & taper & 12.29 & 33.68 & 4.71 & 73.30 & 12.54 & 19.78 \\
\hline constructions & conjugating & 16.06 & 47.07 & 4.80 & 85.32 & 12.32 & 20.71 \\
\hline Total & & 54.12 & 164.91 & 16.48 & 348.52 & 48.32 & 72.48 \\
\hline \multirow{5}{*}{$\begin{array}{l}\text { Images } \\
\text { n drawing }\end{array}$} & 1. axonometry & 12.72 & 48.74 & 6.20 & 79.91 & 7.43 & 22.07 \\
\hline & $\begin{array}{lc}\text { view } & \text { al } \\
\text { 3. local section }\end{array}$ & 11.91 & 40.58 & 5.72 & 67.54 & 7.58 & 19.99 \\
\hline & $\begin{array}{lc}\text { view } & \text { al } \\
\text { 4. broken } & \text { section }\end{array}$ & 8.41 & 42.19 & 6.16 & 67.12 & 6.80 & 20.57 \\
\hline & $\begin{array}{ll}\text { view } & \text { al } \\
\text { 5. stepwise }\end{array}$ & 13.46 & 60.83 & 7.67 & 98.70 & 8.75 & 20.46 \\
\hline & $\begin{array}{l}\text { sectional } \\
\text { view }\end{array}$ & 12.71 & 56.78 & 8.04 & 96.01 & 7.84 & 18.67 \\
\hline \multirow[t]{2}{*}{ Total } & & 59.22 & 249.12 & 33.80 & 409.28 & 38.41 & 101.75 \\
\hline & bolt & 10.49 & 27.30 & 6.87 & 36.68 & 4.81 & 20.26 \\
\hline
\end{tabular}




\begin{tabular}{|c|c|c|c|c|c|c|c|c|}
\hline \multirow{3}{*}{\multicolumn{2}{|c|}{ Connections }} & bolt connection & 6.26 & 24.35 & 4.51 & 39.12 & 4.97 & 22.06 \\
\hline & & stud & 9.00 & 23.52 & 4.49 & 34.90 & 4.39 & 19.23 \\
\hline & & stud connection & 6.51 & 24.32 & 4.51 & 38.80 & 5.06 & 21.23 \\
\hline & & welded joint & 9.45 & 31.93 & 6.52 & 44.00 & 5.81 & 22.29 \\
\hline \multirow{3}{*}{\multicolumn{2}{|c|}{ Total }} & & 41.71 & 131.42 & 26.90 & 193.49 & 25.04 & 105.1 \\
\hline & & Detail \#1 & 1.06 & 28.75 & 2.78 & 32.32 & 3.81 & 15.70 \\
\hline & & Detail \#2 & 0.96 & 30.96 & 3.52 & 34.61 & 4.28 & 15.83 \\
\hline \multirow{3}{*}{\multicolumn{2}{|c|}{ Sketching out }} & Detail \#3 & 0.80 & 30.14 & 3.16 & 33.46 & 5.12 & 15.84 \\
\hline & & Detail \#4 & 0.81 & 24.59 & 3.48 & 31.42 & 4.26 & 15.99 \\
\hline & & Detail \#5 & 0.75 & 29.68 & 3.71 & 37.25 & 5.46 & 16.78 \\
\hline \multirow{6}{*}{$\begin{array}{l}\text { Total } \\
\text { Reading } \\
\text { detailing of } \\
\text { general } \\
\text { drawing }\end{array}$} & & & 4.38 & 144.13 & 16.65 & 169.06 & 22.93 & 80.13 \\
\hline & & Detail \#1 & 2.74 & 24.97 & 3.41 & 30.96 & 4.07 & 17.52 \\
\hline & $\mathrm{d}$ & Detail \#2 & 2.77 & 24.07 & 3.25 & 29.23 & 4.52 & 17.36 \\
\hline & th & Detail \#3 & 2.71 & 23.68 & 3.32 & 28.25 & 4.00 & 16.86 \\
\hline & $\mathrm{e}$ & Detail \#4 & 2.41 & 22.35 & 3.22 & 26.97 & 4.25 & 16.20 \\
\hline & & Assembly drawing & 4.28 & 40.14 & 4.61 & 57.57 & 6.41 & 19.45 \\
\hline \multicolumn{3}{|l|}{ Total } & 14.90 & 135.22 & 17.80 & 172.97 & 23.25 & 87.39 \\
\hline \multicolumn{3}{|c|}{ Drawing by specialty } & 6.65 & 12.25 & 4.16 & 25.06 & 3.77 & 11.72 \\
\hline \multicolumn{3}{|c|}{ Total by section } & 180.8 & 837.08 & 115.78 & 1318.36 & 161.71 & 458.55 \\
\hline \multicolumn{3}{|c|}{ Total by course } & 245.0 & 1001.5 & 143.6 & 1538.2 & 188.23 & 536.3 \\
\hline
\end{tabular}

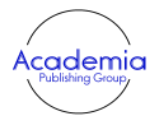

International Journal of Educational Studies Vol. 1, No. 2, pp. 141-148

2018

DOI: 10.53935/2641-533x.v1i2.82

Corresponding Author: Umirbai Ibishev

Funding: This study received no specific financial support.

Received: 29 May 2018

Revised: 5 October 2018

Accepted: 26 November 2018

Published: 21 December 2018

(C) 2018 by the authors; licensee Academic

\begin{tabular}{|c|c|c|c|c|c|c|c|c|c|c|}
\hline Assignment topic & 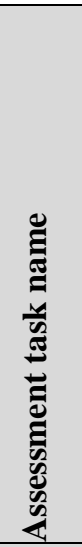 & 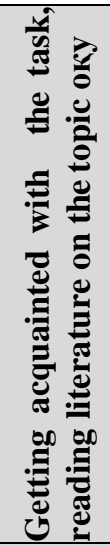 & 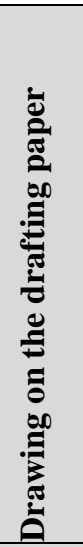 & 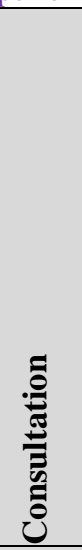 & 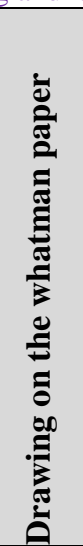 & 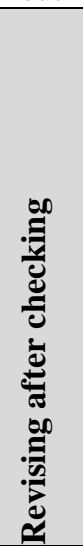 & 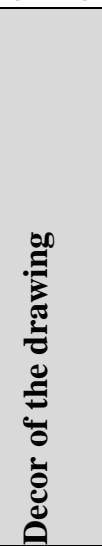 & 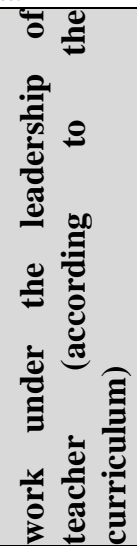 & 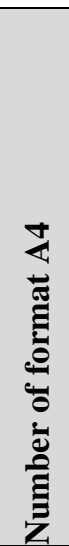 & 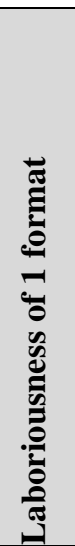 \\
\hline $\begin{array}{l}\text { Geometric } \\
\text { constructions }\end{array}$ & 0.90 & 2.75 & 0.27 & 5.81 & 0.81 & 1.21 & 11.75 & 4 & 4 & 3.94 \\
\hline Images on a drawing & 0.99 & 4.15 & 0.56 & 6.82 & 0.64 & 1.70 & 14.86 & 7 & 5 & 4.37 \\
\hline Connections & 0.70 & 2.19 & 0.45 & 3.22 & 0.42 & 1.75 & 8.73 & 4 & 5 & 2.55 \\
\hline $\begin{array}{l}\text { Assignment \#1 by } \\
\text { Descrintive geometry }\end{array}$ & 081 & 179 & 029 & 244 & 031 & 090 & 6.54 & 2 & 4 & 213 \\
\hline Sketching out & 0.07 & 2.40 & 0.28 & 2.82 & 0.38 & 1.34 & 7.29 & 4 & 5 & 2.26 \\
\hline $\begin{array}{l}\text { Reading and detailing } \\
\text { of } \\
\text { the }\end{array}$ & 0.25 & 2.25 & 0.30 & 2.88 & 0.39 & 1.46 & 7.53 & 3 & 6 & 1.75 \\
\hline $\begin{array}{l}\text { general drawing } \\
\text { Assignment \#2 by }\end{array}$ & & & & & & & & & & \\
\hline Descriptive geometry & 0.25 & 0.95 & 0.18 & 1.22 & 0.14 & 0.40 & 3.14 & 2 & 2 & 2.57 \\
\hline Drawing by specialty & 0.11 & 0.20 & 0.07 & 0.42 & 0.06 & 0.20 & 1.06 & 2 & 2 & 1.53 \\
\hline
\end{tabular}



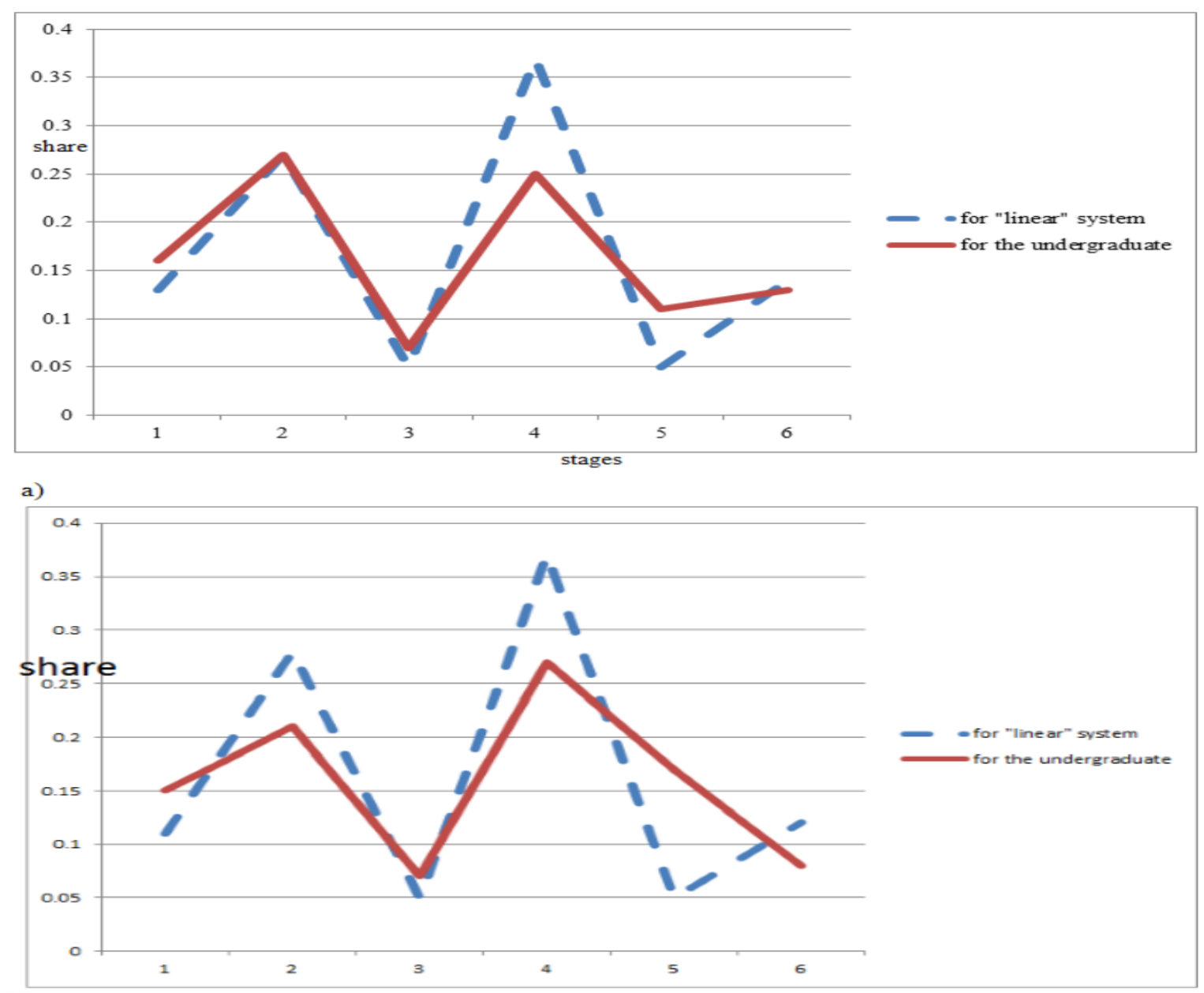

Figure-1. Share indexes' for the assignments by Descriptive geometry: a) for assignment \#1 and b) for all assignments.

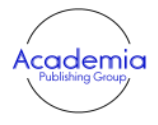

International Journal of Educational Studies Vol. 1, No. 2, pp. 141-148

2018

DOI: 10.53935/2641-533x.v1i2.82

Corresponding Author: Umirbai Ibishev

Funding: This study received no specific

financial support.

Article History:

Received: 29 May 2018
Revised: 5 October 2018

Revised: 5 October 2018

Accepted: 26 November 2018

Published: 21 December 2018

(C) 2018 by the authors; licensee Academic Publishing Group

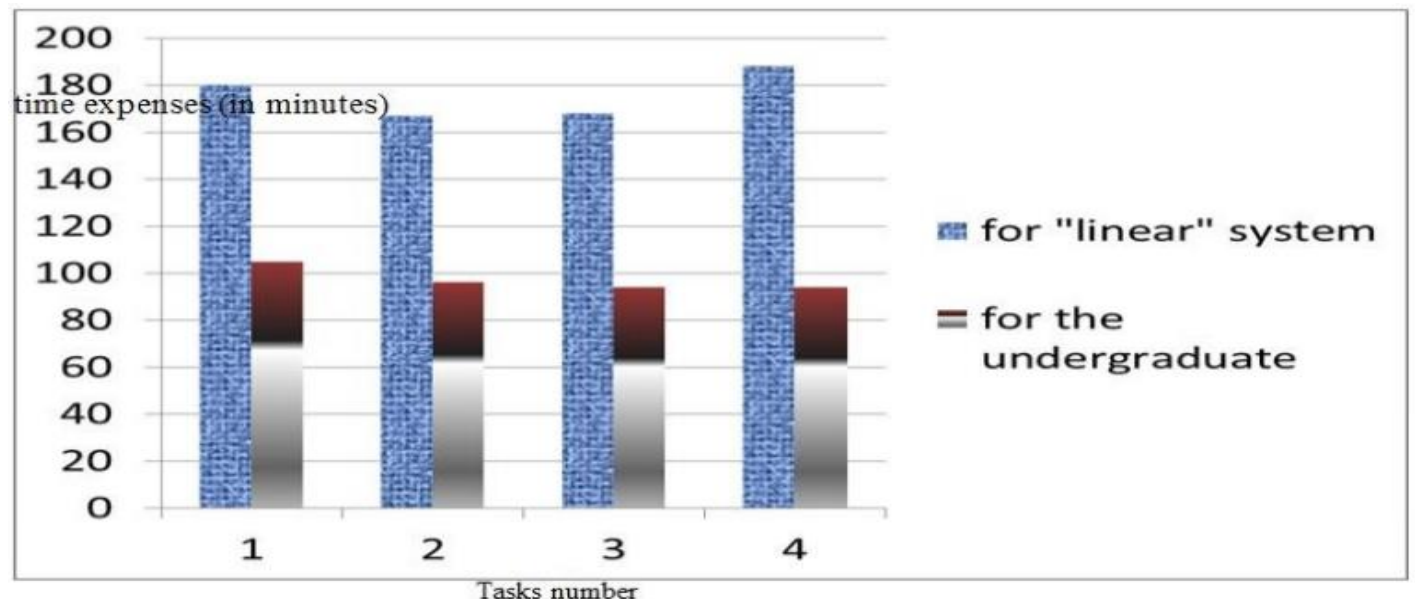

Figure-2. Time expenses for solution of each task of assignment \#1 by Descriptive geometry. 


\section{Tasks}

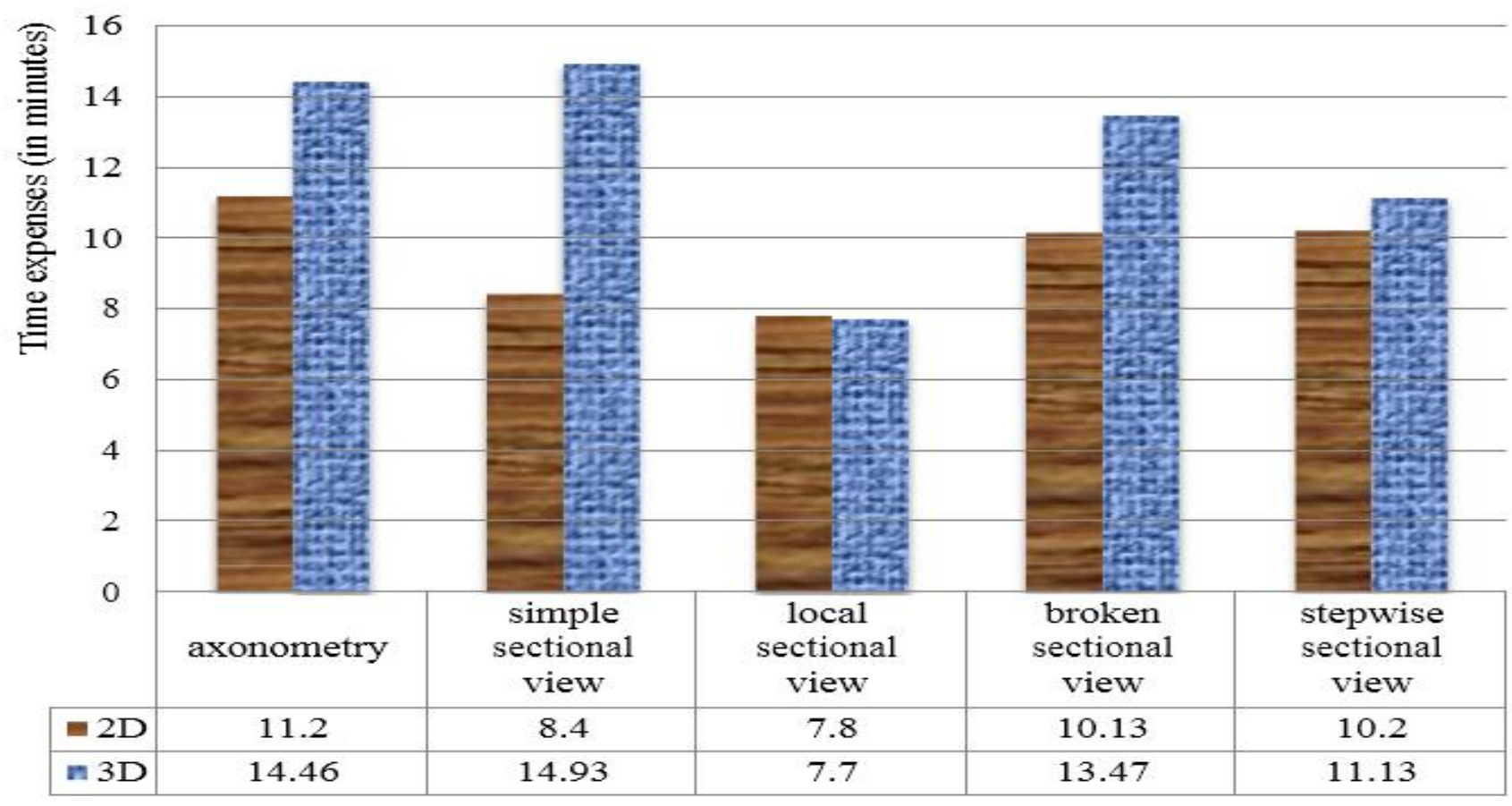

Figure-3. Time expenses when executing of the drawing in 2D and 3D systems.

Making a task on the topic of geometric constructions both in linear system and bachelor degree takes a lot of time. The reason is that this topic was given first and our students often have an inadequate propaedeutic graphic of training level. If we divide the time expenses of each period by the total time expenses, we will find the share by each of them. They are convenient to compare with each other. For example, when we compare the shares for the tasks of Descriptive Geometry, we find the regularity (Figure 1). As we see, in Figure 1a the regularity is preserved completely, but in Figure 1b at the 6th stage there are discrepancies only.

It is a natural phenomenon that the time expenses for a single type task solution are not differed from each other.

In our case this regularity is remained. The example is shown in Figure 2.

The time expenses on A4 format (laboriousness) is lower for Descriptive Geometry than for engineering graphics as in "linear" system and as in the undergraduate. For example, if earlier this value was equal respectively 3 and 4 , by the latest data they are equal to 2.35 and 2.73 respectively. The time expenses in undergraduate decreased relatively by the previous data. That's why:

i) Students choose easier options of tasks as in undergraduate they have the choosing possibility. For example, earlier the students performed the task on the topic "Reading and detailing of the general drawing" on A1 and A2 formats. Currently task by this topic is performed on the formats which in 4 to 2 times smaller than these;

ii) In present, students are fully provided with educational and methodical literature. They perform the task use the textbook, electronic textbook, many tutorials.

We used an expert study for validity grounding the method of a student's independent work volume determining. The validity was assessed by the participation of leading teaching staff of the higher education institutions on the discipline of Descriptive Geometry and Engineering Graphics. In particular, this work has been done at the Kazakh National Agrarian University, K.Satpayev Kazakh National Technical University, Almaty Institute of Energy and Communications, and S. Seifullin Kazakh Agro-Technical University. In order to determine the experts' opinion, they were interrogated. The resulting data were summarized and processed. $100 \%$ of the experts showed that the methodology of determination time expenses on student's independent work are successful, $45 \%$ of them point out that most of time and efforts are required for implementing the methodology, and $30 \%$ believe that the methodology is fully founded. To solve tasks 3 and 4 specified in the introduction the similar to those used previously chronometry card were developed.

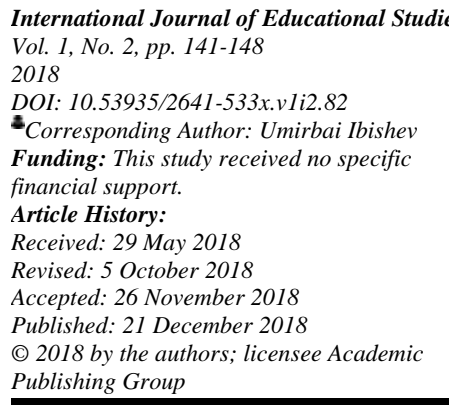


However, they were supplemented with graphs to determine the time expenses when drawings executing in 2D and 3D systems. Experiments results conducted in the Financial Academy (Astana) with students of the specialty "Computer Science and Software" in 2016-2017 showed the following.

The time expenses on showing the same drawings that were previously showed on the whatman paper and using the computer program COMPAS decreased by $6 \ldots 11$ times depending on the topic of the assignment.

It is known that the drawing of a detail which use the computer can be showed in two ways:

- In the 2D system with use of its tools in order similar to the drawing on the whatman paper;

- In the 3D system, when three-dimensional model is pre-constructed, then with its help a flat drawing is obtained.

Analysis of the data in Tables 1-3 shows that the fourth stage (drawing on whatman paper) accounts for $29 \%$ (see Table 1) or 31-34\% (see Tables 2 and 3) of all expenses (for Descriptive Geometry) and 42-44\% (see Tables 2 and 3) of all expenses (for Engineering Graphics). This circumstance can be used for more rapid data collection, namely, the time expenses to determine not for all stages, but for the fourth stage only. Then the total time expenses approximately can be determined as follows: the time required for the fourth stage to multiplie by 3 (for Descriptive Geometry) or by 2.5 (for Engineering Graphics).

So, to use the methodology at least the time expenses on the fourth phase of drawing executing should be determined by chronometry cards.

The time expenses on A4 format (laboriousness) can be used to determine the student's independently work volume. For this purpose, laboriousness should be multiplied by the planned numbers of A4 formats.

\section{Conclusion}

We have shown that the methodology of the student's independently work designing on graphic disciplines is theoretical grounded and is conveniented to use in practice. It is proved by the fact that the experts evaluated the method as valid, and the experimental work that has been conducted for many years at different universities has been with a positive result. The obtained data gives the ability to determine the student's independently work laboriousness. At the same time we have determined the effectiveness' of drawings with using computer. Thus, the tasks were fully implemented.

\section{References}

Kolesnikova, G. I. (2015). Methodology of psychological and pedagogical research (Vol. 320). Moscow: Phoenix.

Nabi, Y. A. (1996). Scientific and pedagogical bases of graphic training of future engineers in higher educational institutions (Vol. 367). Almaty: Monograph.

Nabi, Y. A., Kampitova, G., \& Kucherbaev, C. K. (2009). The structure of the budget of time for students of KazNAU / Collection of articles of the scientific and practical conference. Paper presented at the Science and Education for the Village" and a Round Table Dedicated to the 100th Anniversary of the Birth of A.I. Baraev (May 30, 2008, October 24, 2008) Almaty.

Vdovin, E. N. (1984). To planning the volume of assignments at the course of descriptive geometry and engineering drawing. In the collection: Methodical developments on the activation of students' academic work (pp. 14-20). Almaty: KazSKhI.

Verhela, A. P. (1988). Didactic bases of optimization of process of training to disciplines of high school. Diss. ...Dr. Ped Sciences. M. 210. 